\title{
Mechanical and thermal properties of PP/PBT blends compatibilized with triblock thermoplastic elastomer
}

\author{
Wojciech Ignaczak, Kinga Wiśniewska, Jolanta Janik, Mirosława El Fray* \\ West Pomeranian University of Technology, Szczecin, Polymer Institute, ul. Pułaskiego 10, 70-322 Szczecin, Poland \\ *Corresponding author: e-mail: mirfray@zut.edu.pl
}

\begin{abstract}
A linear triblock copolymer, poly(styrene-b-etylene/butylene-b-styrene)(SEBS) thermoplastic elastomer (TPE) grafted with maleic anhydride was used for compatibilization of PP/PBT blends. PP/PBT blends of different mass ratios 60/40,50/50, 40/60 were mixed with 2.5, 5.0 and 7.5 wt.\% of SEBS copolymer in a twin screw extruder. Differential scanning calorimetry and dynamic mechanical analysis were performed to define the phase structure of PP/PBT blends. TPE with a rubbery mid-block shifted the glass transition of PP/PBT blend towards lower temperatures, and significant decrease the crystallization temperature of a crystalline phase of PP component was observed. The influence of the amount of compatibilizer and the blend composition on the mechanical properties (tensile and flexural strengths, toughness and moduli) was determined. Addition of $5 \mathrm{wt} . \%$ of a triblock TPE led to a three-fold increase of PP/PBT toughness. A significant increase of impact properties was observed for all materials compatibilized with the highest amount of SEBS copolymer.
\end{abstract}

Keywords: polymer blends, PP/PBT, triblock copolymer, SEBS, compatibilization.

\section{INTRODUCTION}

In the field of contemporary research on polymeric materials one of the most important problems that face modern science is the miscibility of polymers. Blending polymers is a very convenient method to obtain completely new polymeric materials without necessity, often very troublesome, synthesis of new polymers. The biggest advantage of the polymer blend is its significantly improved performance compared to the individual components of the blend. Moreover, the mixing process of different polymers does not absorb significant amount of the energy compared to the synthesis of new monomers and polymers, what makes them cheaper, and thus economically justified. Another advantage of polymer blends is the ability to design the material during the compounding step, by manipulating the molar or mass ratio of the individual components on the feed. According to the definition, a polymer mixture is a macroscopically homogeneous mixture of two or more various types of polymers or copolymers. Miscible polymer mixture is homogeneous mixture when $\Delta \mathrm{G}_{\mathrm{M}} \approx \Delta \mathrm{H}_{\mathrm{M}} \leq 0$ [1]. Immiscible polymer blend is obtained when $\Delta \mathrm{GM} \approx \Delta \mathrm{H}_{\mathrm{M}}>$ $0^{1}$. Polyolefines, representing $48 \%$ of world production of plastics in 2011, can be modified in a wide composition range by mixing them with other engineering polymers, including polyesters. Generally, blends prepared from the two immiscible polymers are very brittle and need to be compatibilized to increase their toughness ${ }^{2-5}$. Commonly used compatibilizers of polyolefin/polyester or a polyolefin/polyamide systems are graft copolymers ${ }^{6}$. The most frequently used monomers for preparation of efficient compatibilizers for these systems are maleic anhydride, vinyl monomers, and itaconic and methacrylic copolymers containing reactive functional groups able to form hydrogen bonds between two or more polymer chains $s^{6-8}$. Other systems are based on highly elastic linear block copolymers comprising of ethylene/butylene rubber midblock and amorphous styrene terminal blocks (S-EB-S). Those materials belong to the group of thermoplastic elastomers (TPE), in which a thermoplastic is combined with the elastomer phase. TPEs are in general composed of elastomeric chains, responsible for the flexibility and the resistance for material cracking, and thermoplastic segments (blocks) responsible for exceptional mechanical properties, chemical resistance and durability. TPE behaves like a rubber at the room temperature, showing large elasticity (up to $1000 \%$ ) and thermoplastic resin at high temperatures facilitating its processing. Compositional variables, namely block length and content, are known to affect the degree of phase separation, phase mixing and degree of crystallinity and accordingly the polymer properties ${ }^{\mathbf{9}} \mathbf{1 0}$.

The aim of this work is to evaluate the compatibilization efficiency of polypropylene (PP)/poly(butylene terephthalate) (PBT) (PP/PBT) immiscible blends with the use of a maleic anhydride grafted linear SEBS block copolymer (SEBS-g-MAH). The influence of the compatibilizer amount on mechanical and thermal properties was specifically evaluated.

\section{EXPERIMENTAL}

\section{Material selection}

Nucleated polypropylene (PP) (Moplen HP 548R) as a homopolymer was obtained from Basell Polyolefins. The neat poly(butylene terephthalate) (PBT) resin (Celanex 2500) appropriate for outdoor applications was obtained from Ticona Engineering Polymers. Substrates were selected based on the mass melt flow index (MFI) at the blend processing temperature $\left(\mathrm{MFI}_{\mathrm{PP}}: \mathrm{MFI}_{\mathrm{PBT}}, 30: 37 \mathrm{~g} / 10 \mathrm{~min}\right)$. The thermoplastic elastomer, triblock copolymer, poly(styrene-b-ethylene/butylene-b-styrene) grafted with maleic anhydride (SEBS-g-MAH) (Kraton FG 1901GT) used as compatibilizer was obtained from Kraton LLC Polymers. The styrene fragments content in the SEBS block copolymer was 30 wt.\%

\section{Melt blending}

$\mathrm{PP} / \mathrm{PBT}$ blends in various mass ratios $(60 / 40 ; 50 / 50$; $40 / 60 \mathrm{wt} \%$ ) were prepared using extrusion process. The melt blending was carried out using a $16 \mathrm{~mm}$ co-rotating twin-screw extruder (Thermo Prism) with L/D $=40$ and 
barrel temperature was ranging from 220 to $250^{\circ} \mathrm{C}$ and nozzle temperature was $260^{\circ} \mathrm{C}$. Screw rotation speed and dosing were determined to achieve specified outlet pressure (from 18 to 25 bar). The amounts of the compatibilizer used during the process were 2.5, 5.0 and 7.5 wt $\%$ respectively. Polymer blends after extrusion were cut into pellets and the extruded pellets were dried for 24 hours at $60^{\circ} \mathrm{C}$ in vacuo afterwards. Specimens were injection molded according to PN-EN ISO 527-2 standard using injection moulding machine BOY 32. Processing parameters were selected with respect to the standardized parameters referring to the compound with higher melting temperature.

\section{Blend characterization}

Q100 DSC (TA Instruments Inc., USA) apparatus was used for thermal properties evaluation (heating/cooling rate of $10{ }^{\circ} \mathrm{C} / \mathrm{min}$, from -90 to $300^{\circ} \mathrm{C}$ ). Samples were weighted $(\sim 10 \mathrm{mg})$ into aluminum pans and hermetically sealed before the analysis. The second heating cycle was used to evaluate the thermal properties. Q800 DMA (TA Instruments Inc., USA) apparatus operating in a bending mode was used for the detection of the glass transition temperature $\left(\mathrm{T}_{\mathrm{g}}\right)$, which was taken as maximum of loss modulus (E”). The relaxation spectrum was scanned from $-80^{\circ}$ to $100^{\circ} \mathrm{C}$ with a frequency of $1 \mathrm{~Hz}$ and a heating rate of $3^{\circ} \mathrm{C} / \mathrm{min}$. Prepared specimens (dog-bones S1) were conditioned for $48 \mathrm{~h}$ at the room temperature and then subjected to characterization of thermal properties and mechanical tests. Mechanical tests were performed with an Instron 3366 machine following PN-EN ISO 527-2 and PN-EN 13566-4 standards. The strain rate for Young's Modulus measurement was $1 \mathrm{~mm} / \mathrm{min}$. Elongation at break was evaluated at crosshead speed $10 \mathrm{~mm} /$ min. Toughness was evaluated as the area under the stress-strain curve till the yield point. Charpy notched test was performed to define the impact properties of PP/PBT blends according PN-EN ISO 179-1:2000 using 0,5 J Zwick/Roel Hammer with A type notch samples.

\section{RESULTS AND DISCUSSION}

\section{Thermal properties}

$\mathrm{PP} / \mathrm{PBT}$ blend is immiscible due to significant difference in free energy of mixing, $\Delta \mathrm{G}_{\mathrm{M}}$, which is well above $1^{1}$. The blend immiscibility is reflected by the appearance of two separated melting transitions, $\mathrm{T}_{\mathrm{m} 1}$ and $\mathrm{T}_{\mathrm{m} 2}$, ascribed to PP and PBT phases, as can be seen on representa- tive thermograms for PP/PBT 50/50 blend (Fig. 1). By introducing block copolymer as compatibilizer, some changes should be observed in melting region, specifically temperature shift, which will reflect the occurrence of the phase mixing ${ }^{11-13}$.

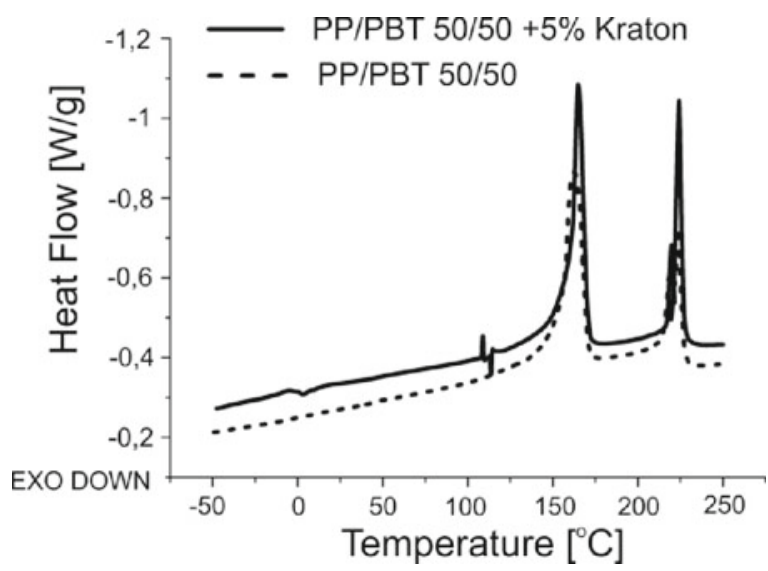

Figure 1. DSC thermograms (second heating) for PP/ PBT 50/50 with and without compatibilizer

As can be seen from Table 1, significant changes in the melting enthalpies, $\Delta \mathrm{H}_{\mathrm{mPP}}$ and $\Delta \mathrm{H}_{\mathrm{mPBT}}$ were noticed. In general, larger drop of melting enthalpy of PP phase (10.7 $\mathrm{J} / \mathrm{g}$ ) was observed for blend containing higher amount of PP in a blend (60/40 system) while modified with higher amount of Kraton in comparison to the 40/60 system (only $4.0 \mathrm{~J} / \mathrm{g}$ drop). This is an evidence for better chemical affinity between Kraton (SEBS-g-MAH) copolymer and polypropylene phase and thus better compatibilization effect in polymer blends containing higher amount of PP phase, similar to our earlier work ${ }^{14}$.

The better interaction between Kraton block copolymer and PP phase is also reflected in crystallization temperature by higher differences in $T_{c}$ observed for PP phase as compared to PBT phase in all composition range. The representative thermograms for the $\mathrm{PP} / \mathrm{PBT}$ $50 / 50$ systems with and without compatibilizer are given in Figure 2.

For PP/PBT 50/50 blend, the crystallization enthalpy of PP phase for the blend compatibilized with $7.5 \mathrm{wt} \%$ of Kraton is decreasing to larger extent (from 64.7 to 53.5 $\mathrm{J} / \mathrm{g}$ ) as compared to PBT phase (from 25 to $21,3 \mathrm{~J} / \mathrm{g}$ ).

The glass transition temperature, $\mathrm{T}_{\mathrm{g}}$ was determined by dynamic mechanical thermal analysis (DMTA) since it was difficult to detect this transition using DSC. The $T_{g}$ value was determined as the maximum of the E" curve and values are provided in Table 2 and 3.

Table 1. Melting temperatures and melting enthalpies of PP/PBT blends

\begin{tabular}{|c|c|c|c|c|c|c|c|c|}
\hline $\begin{array}{l}\text { PP/PBT } \\
+ \text { SEBS- } g-M A\end{array}$ & $\begin{array}{l}\mathrm{T}_{\mathrm{m}}{ }^{\mathrm{PP}} \\
{\left[{ }^{\circ} \mathrm{C}\right]}\end{array}$ & $\mathrm{T}_{\mathrm{m}}{ }^{\mathrm{PBT}}\left[{ }^{\circ} \mathrm{C}\right]$ & $\begin{array}{l}\mathrm{T}_{\mathrm{c}}^{\mathrm{PP}} \\
{\left[{ }^{\circ} \mathrm{C}\right]}\end{array}$ & $\mathrm{T}_{\mathrm{C}}{ }^{\mathrm{PBT}}\left[{ }^{\circ} \mathrm{C}\right]$ & $\Delta \mathrm{H}_{\mathrm{m}}{ }^{\mathrm{PP}}[\mathrm{J} / \mathrm{g}]$ & $\begin{array}{c}\Delta \mathrm{H}_{\mathrm{m}}^{\mathrm{PBT}} \\
{[\mathrm{J} / \mathrm{g}]}\end{array}$ & $\Delta \mathrm{H}_{\mathrm{c}}{ }^{\mathrm{PP}}[\mathrm{J} / \mathrm{g}]$ & $\Delta \mathrm{H}_{\mathrm{c}}{ }^{\mathrm{PBT}}[\mathrm{J} / \mathrm{g}]$ \\
\hline $60 / 40 / 0$ & 165.4 & 223.8 & 128.1 & 201.5 & 65.1 & 18.2 & 76.3 & 19.1 \\
\hline $60 / 40 / 2.5$ & 165.1 & 224.1 & 124.4 & 199.9 & 59.4 & 19.1 & 71.3 & 19.0 \\
\hline $60 / 40 / 7.5$ & 164.7 & 224.2 & 122 & 199.7 & 54.4 & 19.6 & 73.2 & 17.3 \\
\hline $50 / 50 / 0$ & 164.2 & 224.4 & 127.5 & 202.5 & 50.9 & 19.4 & 64.7 & 25.0 \\
\hline $50 / 50 / 2.5$ & 163.7 & 224.9 & 121.9 & 199.3 & 44.5 & 20.9 & 60.1 & 24.9 \\
\hline $50 / 50 / 5$ & 164.7 & 224.6 & 123.1 & 199.9 & 40.8 & 23.9 & 51.0 & 32.2 \\
\hline $50 / 50 / 7.5$ & 167.4 & 226.7 & 118.8 & 196.9 & 39.3 & 20.5 & 53.5 & 21.3 \\
\hline $40 / 60 / 0$ & 165.5 & 224.9 & 126.5 & 203.2 & 44.1 & 24.4 & 50.2 & 38.7 \\
\hline $40 / 60 / 2.5$ & 165.1 & 225.1 & 122.1 & 199.2 & 41.0 & 25.2 & 49.7 & 31.2 \\
\hline $40 / 60 / 5$ & 164.7 & 224.7 & 121.7 & 199.9 & 40.9 & 26.5 & 46.9 & 32.3 \\
\hline $40 / 60 / 7.5$ & 165 & 225.1 & 120.2 & 198.9 & 40.1 & 27.2 & 51.9 & 28.3 \\
\hline
\end{tabular}




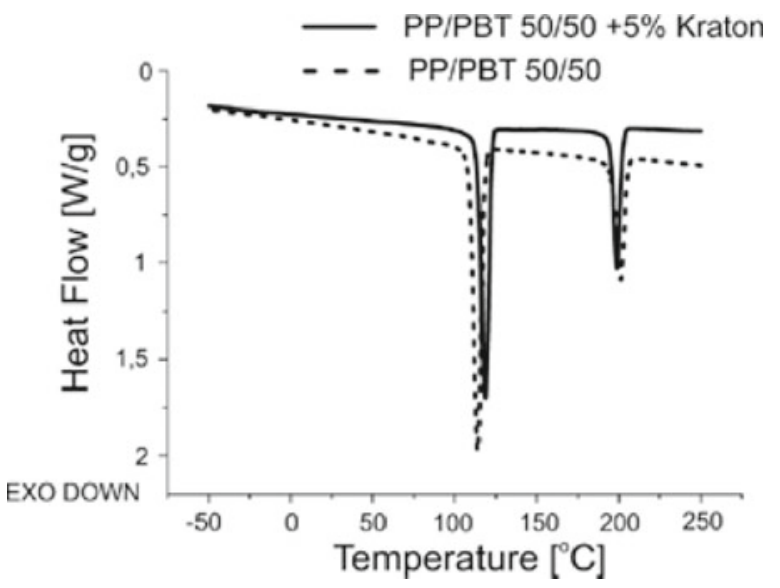

Figure 2. DSC thermograms (cooling run) for PP/PBT $50 / 50$ with and without compatibilizer

Two glass transition temperatures were observed for all polymer blends. First one, at lower temperature, corresponds to PP amorphous phase; second one in higher temperature corresponds to PBT. After the addition of

a compatibilizer, a small shift in glass transition temperatures to lower values were observed. This behavior is illustrated on the example of PP/PBT 50/50 blend with addition of different amount of Kraton block copolymer (Table 3).

The shifts towards lower temperatures are caused by the highly amorphous nature of the triblock copolymer (Kraton), specifically high content (70 wt.\%) of rubbery EB block (the $\mathrm{T}_{\mathrm{g}}$ of rubbery mid-block is approx. $-40^{\circ} \mathrm{C}$ ). Thus, with increasing amount of a compatibilizer more significant shifts towards lower temperatures were found.

\section{Mechanical performance}

Mechanical properties were evaluated from the quasi-static measurements performed with an Instron 3366 machine. Tensile and flexural properties for PP/PBT systems were determined and compared with the data for the neat polypropylene. The tensile modulus and tensile strength data are presented in Figure 3 and Figure 4, respectively.
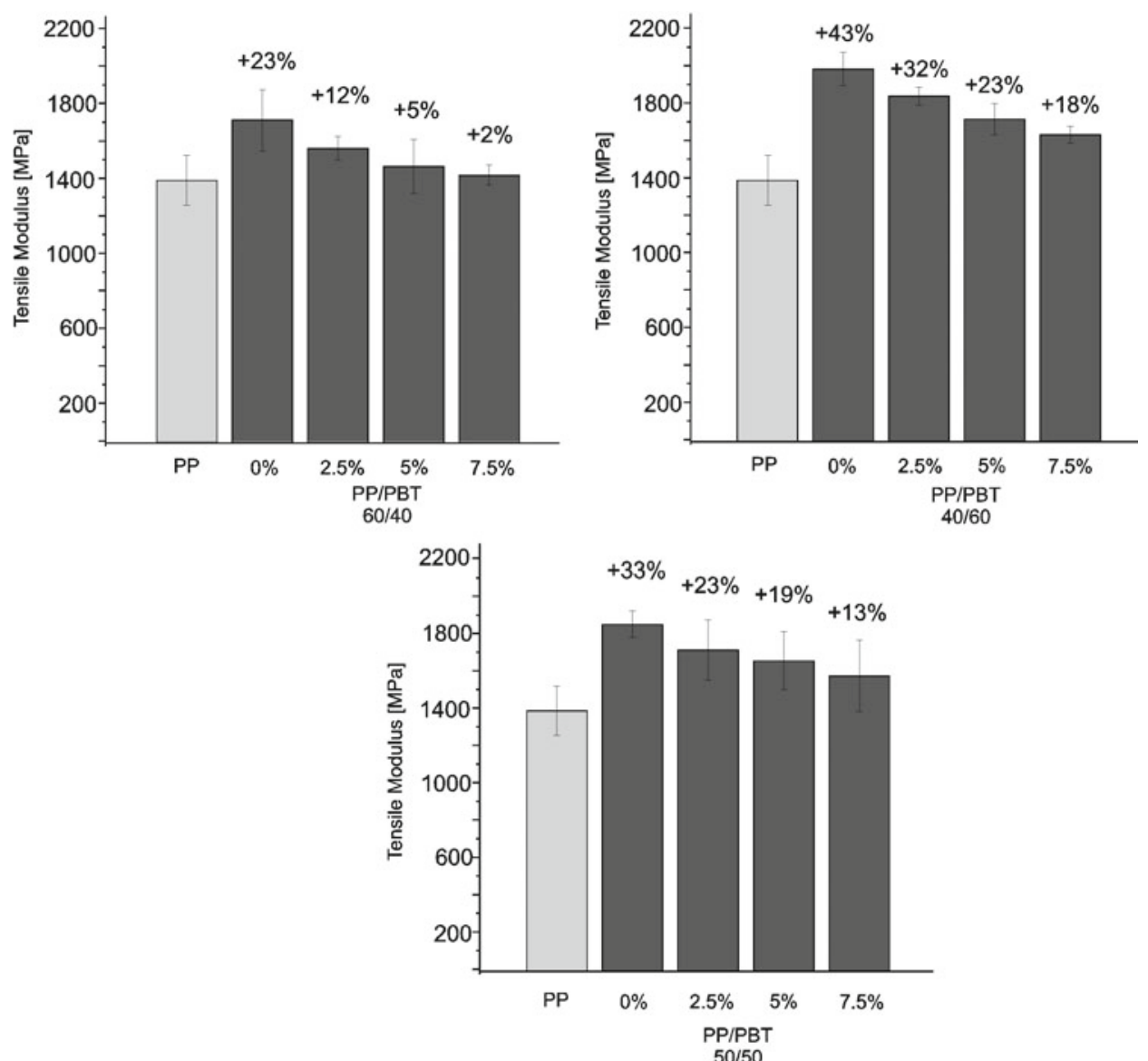

Figure 3. Tensile modulus of PP/PBT blends compatibilized by SEBS-g-MAH

Table 2. The glass transition temperature, $\mathrm{T}_{\mathrm{g}}$ for incompatible PP/PBT blends taken as the maximum of loss modulus (E”)

\begin{tabular}{|l|c|c|c|c|c|}
\hline & & PP & PBT & PP/PBT $2.5 \%$ & PP/PBT $5 \%$ \\
\hline $\operatorname{Tg}\left(\mathrm{E}^{\prime}{ }_{\max }\right)\left[{ }^{\circ} \mathrm{C}\right]$ & \multirow{2}{*}{$14.2 \pm 0.2$} & \multirow{2}{*}{$62.2 \pm 0.2$} & $9.5 \pm 0.3$ & $\begin{array}{c}10.3 \pm 0.2 \\
(59.3 \pm 0.4)\end{array}$ & $\begin{array}{c}10.0 \pm 0.3 \\
(63.8 \pm 0.3)\end{array}$ \\
\hline
\end{tabular}

*numbers in brackets are related to PBT phase.

Table 3. The glass transition temperature, $\mathrm{T}_{\mathrm{g}}$ for PP/PBT 50/50 blends compatibilized with 2.5 , 5 and 7.5 of Kraton

\begin{tabular}{|l|c|c|c|c|c|}
\hline & PP & PBT & PP/PBT 2.5\% & PP/PBT $5 \%$ & PP/PBT 7.5\% \\
\hline $\operatorname{Tg}\left(\mathrm{E}^{\prime \prime}{ }_{\max }\right)\left[{ }^{\circ} \mathrm{C}\right]$ & $14.2 \pm 0.2$ & $62.2 \pm 0.2$ & $13.6 \pm 0.3$ & $12 \pm 0.2$ & $11.1 \pm 0.2$ \\
$(58.5 \pm 0.4)$ & $(57.3 \pm 0.4)$ & $(56.9 \pm 0.3)$ \\
\hline
\end{tabular}

*numbers in brackets are related to PBT phase. 

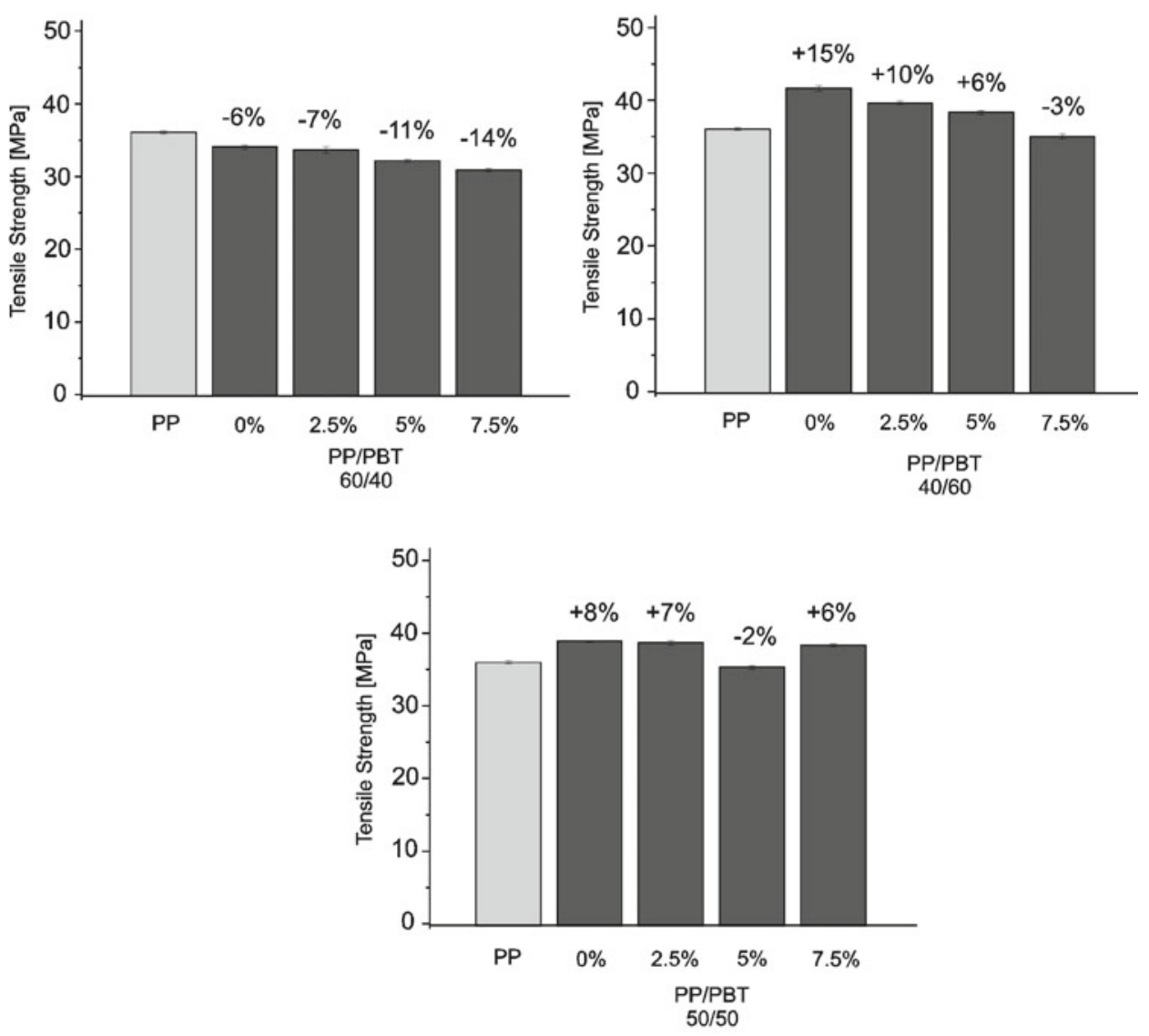

Figure 4. Tensile strength of PP/PBT blends compatibilized by SEBS- $g$-MAH

The tensile properties (strength and modulus) for incompatible $\mathrm{PP} / \mathrm{PBT}$ blends were compared to the values of PP, and no significant changes in material properties were found. The tensile modulus (Fig. 3) for compatibilized blends directly depends on the chemical composition of the blend. The highest modulus was reached for the composition PP/PBT 40/60. With increasing amount of the compatibilizer, modulus values are decreasing. For two mass ratios (40/60 and 50/50) of PP/PBT blends, the promising results of the tensile modulus were obtained. Moreover, an optimal amount of the triblock copolymer was determined and it is in a range between 5.0-7.5 wt.\%. The tensile strength can also be modified by tailoring the composition of PP/PBT blend and the compatibilizer amount. Applying highly elastic compatibilizer, only PP/ PBT 40/60 and 50/50 polymer blends have reached better strength than the neat PP.

The calculation of toughness values for uncompatibilited system and compatibilized only with $5 \mathrm{wt} \%$ of Kraton revealed significant differences, showing two-, or even three-fold increase. The results of toughness evaluated from the stress-strain curves for each blend composition containing $5 \mathrm{wt} \%$ of block copolymer are given in Table 4.

The flexural tests data comprising flexural modulus and flexural strength are presented in Figure 5 and Figure 6, respectively.
In general, the flexural properties of uncompatibilized blend were enhanced as compared to polypropylene. Addition of SEBS-g-MAH improves flexural properties at low concentration and more significant improvement is observed for the blend containing lower amount of PP phase (40/60). The flexural modulus decreases with increasing amount of Kraton and increasing amount of PP phase.

The highest values of flexural strength were also obtained for the PP/PBT 40/60 blend. In comparison with polypropylene, significant increase $(20-30 \%)$ in flexural properties (strength and modulus) was achieved, and it depends from the compatibilizer amount introduced to the polymer blend. For other systems, it can be noticed that the content of the compatibilizer up to $7.5 \mathrm{wt} . \%$ does not significantly reduce the mechanical properties of the blend. Furthermore, an improvement in blend processing with increasing content of the block copolymer was noticed. It was also found that the PP/PBT 40/60 systems showed the best processability.

Figure 7 present the results of Charpy notched impact test for polymer blends with different mass ratios of each component. The values for polypropylene were used as a reference.

It was found that significant improvement in impact properties was noticed with increasing amount of PBT in polymer blend. Accordingly to percentage addition of block copolymer impact strength for each polymer

Table 4. Toughness of PP/PBT blends

\begin{tabular}{|l|c|c|c|c|c|c|}
\hline $\begin{array}{l}\text { PP/PBT/SEBS } \\
\text { ratio }\end{array}$ & $60 / 40 / 0$ & $60 / 40 / 5$ & $50 / 50 / 0$ & $50 / 50 / 5$ & $40 / 60 / 0$ & $40 / 60 / 5$ \\
\hline $\begin{array}{l}\text { Toughness } \\
{\left[\mathrm{kJ} / \mathrm{m}^{2}\right]}\end{array}$ & 28 & 104 & 47 & 125 & 36 & 147 \\
\hline
\end{tabular}



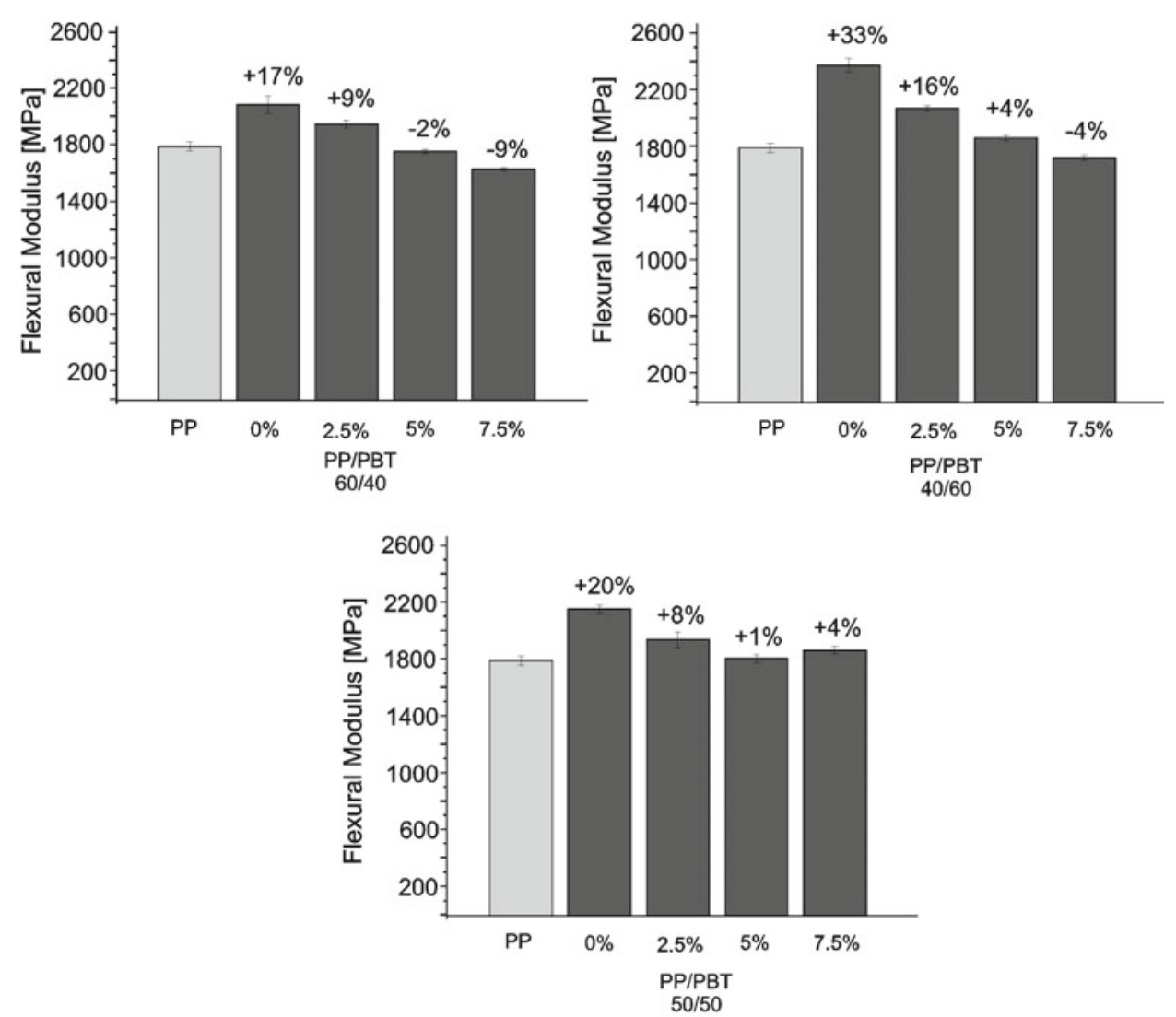

Figure 5. Flexural modulus of PP/PBT blends compatibilized with SEBS-g-MAH
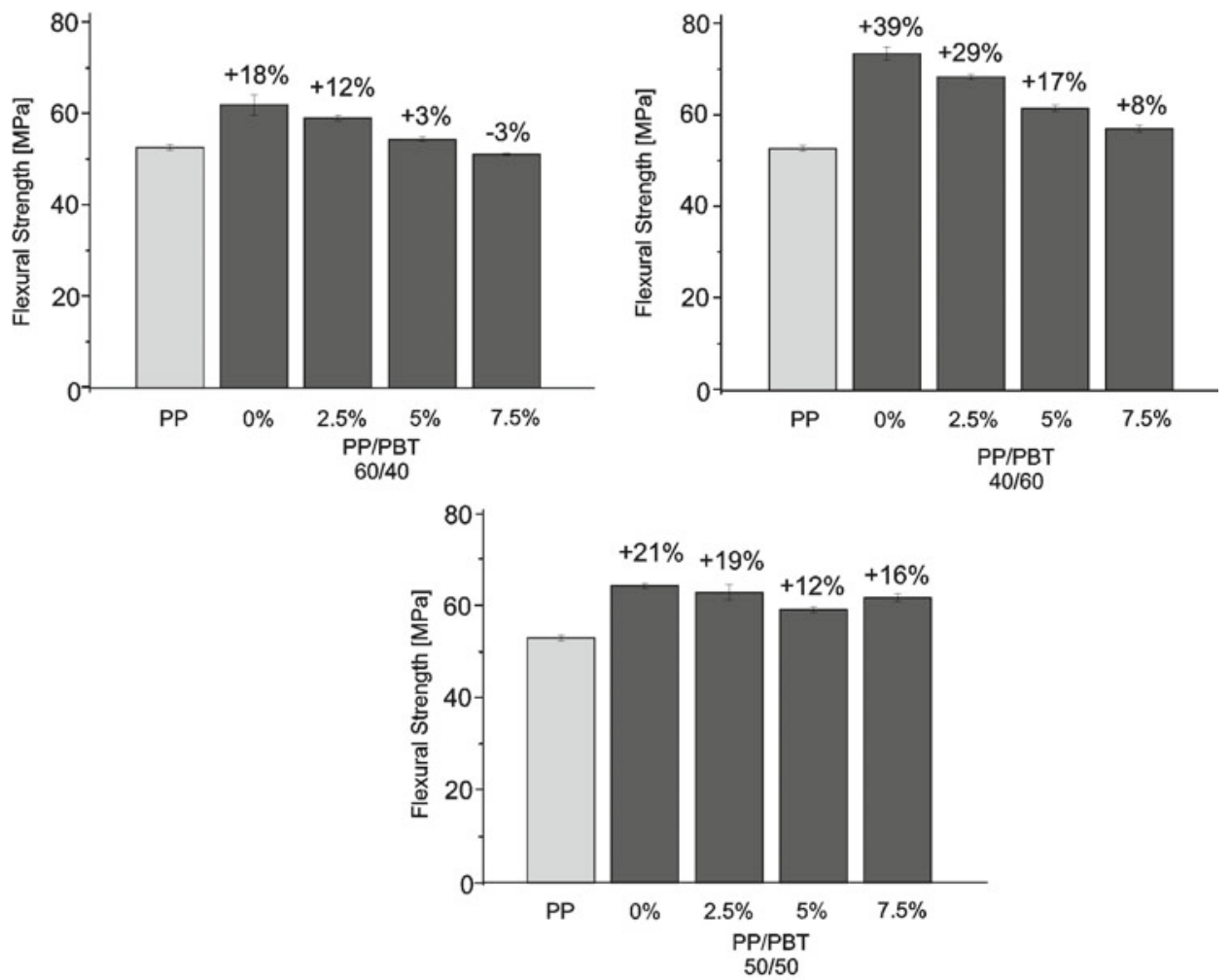

Figure 6. Flexural strength of PP/PBT blends compatibilized with SEBS-g-MAH

blend increases as well. From energy consumption point of view during the test, it is appropriate to assume that uncompatibilized PP/PBT blends are definitely not suitable for outdoor applications. After compatibilization such blends can be applied in many fields.

\section{CONCLUSIONS}

Triblock copolymer, poly(styrene-b-ethylene/butylene-bstyrene), commercially available Kraton was used as a compatibilizer for polyolefin/polyester systems, namely PP/PBT blend. The mechanical tests and thermal analysis confirmed that SEBS-g-MAH can be used as an efficient compatibilizer for this system, specifically for the 40/60 composition. The presence of two glass transition 

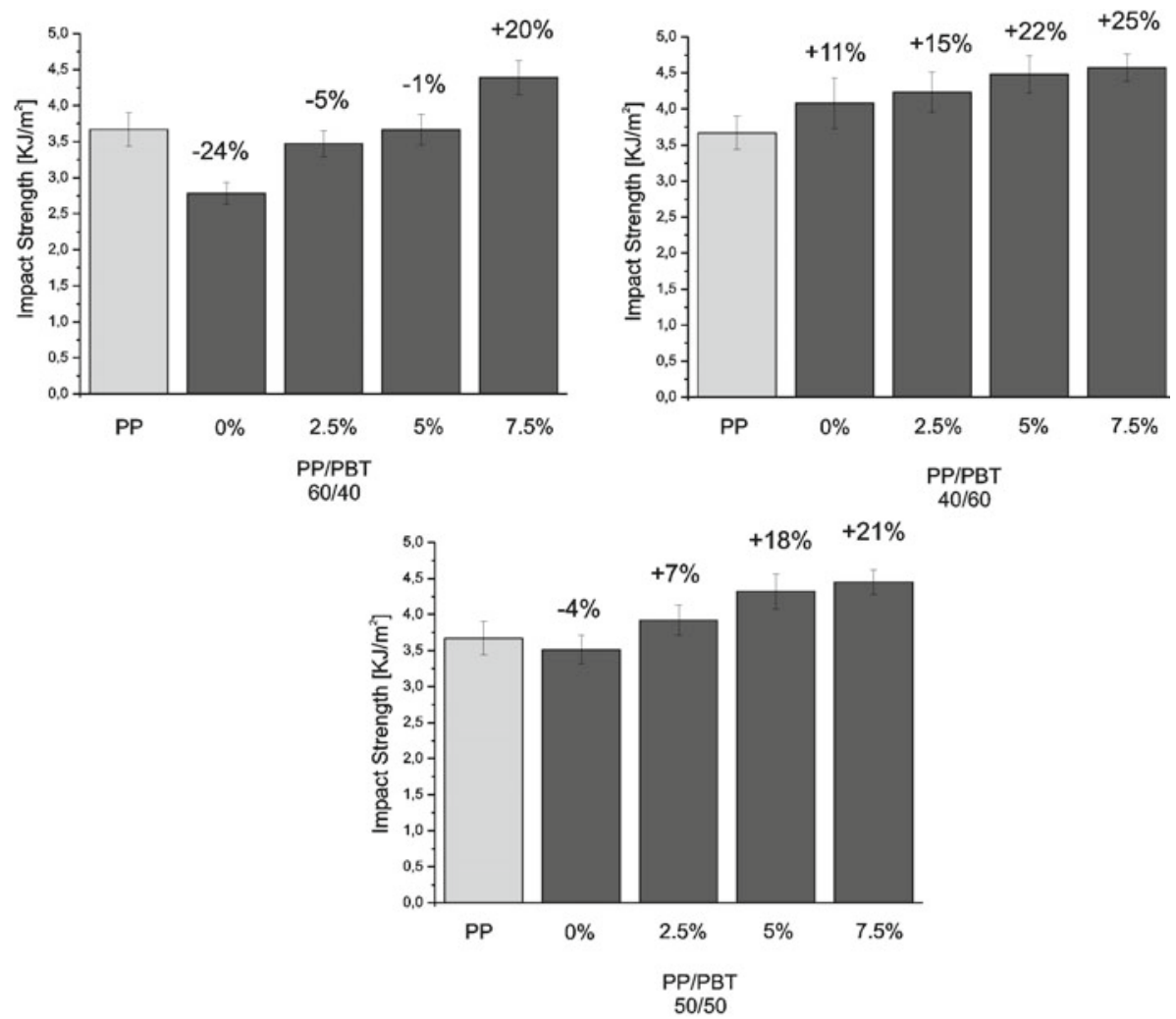

Figure 7. Impact properties of PP/PBT blends compatibilized by SEBS-g-MAH block copolymer

temperatures indicate that the polymer system does not create a single phase but the mechanical tests and differential scanning calorimetry results confirmed the compatibilization effect. Increasing PBT content makes the blend stiffer, stronger and tougher. For specific blend composition (40/60), the ability to absorb the energy without failure increases with increasing compatibilizer content. Moreover, for each blend composition, its impact strength increases with increasing both compatibilizer and PBT content.

\section{ACKNOWLEDGEMENT}

The authors gratefully acknowledge the funding of the European Union Seventh Framework Programme (FP7/2007-2013) within the project HarWin under grant agreement $\mathrm{N}^{\mathrm{o}} 314653$ (www.harwin-fp7.eu).

\section{LITERATURE CITED}

1. Bates F.S., (1991). Polymer-Polymer phase behavior, Science 251, 898-905 DOI:10.1126/science.251.4996.898.

2. Traugott, T.D., Barlow, J.W. \& Paul, D.R.J. (1983). Mechanical compatibilization of high density polyethylenepoly(ethylene terephthalate) blends, Appl. Polym. Sci. 28, 2947-2959. DOI: 10.1002/app.1983.070280922.

3. Barlow, J.W. \& Paul, D.R. (1984). Mechanical compatibilization of immiscible blends, Polym. Eng. Sci. 24, 525 DOI: 10.1002/pen.760240804.

4. Bataille, P., Boisse, S. \& Schreiber, H.P. (1987). Mechanical properties and permeability of polypropylene and poly(ethylene terephthalate) mixtures, Polym. Eng. Sci. 27, 622, DOI: 10.1002/pen.760270904.

5. Janik, J., Krolikowski, W. \& Peczek, P., Polyester terephthalate and polyolefine blends- procedure preparing, 06-12-27 PL348950.

6. El Fray, M. \& Słonecki, J. (1999). Multiblock terephthalate copolymer as impact modifier for poly(propylene)/ poly(butylene terephthalate) blends, Angew. Mac- rom. Chem. 266, 30-36. DOI: 10.1002/(SICI)1522-9505(19990501)266:1<30::AID-APMC30>3.0.CO;2-3.

7. He, Y., Zhu, B. \& Inoue, Y. (2004). Hydrogen bonds in polymer blends, Prog. Polym. Sci. 29, 1021-1051. DOI: 10.1016/j.progpolymsci.2004.07.002.

8. Tsai, C.H. \& Chang, F.C. (1996). Polymer Blends of PBT and PP Compatibilized by Ethylene-co-glycidyl Methacrylate Copolymers, J. Appl. Polym. Sci. 61, 321-332. DOI: 10.1002/(SICI)1097-4628(19960711)61:2<321::AIDAPP15>3.0.CO;2-6.

9. Paik Sung, C.S. \& Schneider, N.S. (1977). In: Klempner D. \& Frisch K.C., editors. Polymer alloys, New York: Plenum Press, 251.

10. Van Bogart, J.W.C., Lilaonitkul, A. \& Cooper, S.L. (1979). Morphology and Properties of Segmented Copolymers Adv. Chem. Ser. 176, 3. DOI: 10.1021/ba-1979-0176.ch001.

11. Janik, J., Krolikowski, W. \& Peczek, P. (2004). Polymer blends PET/PE-LD and PET/PP with a new compatibilizer, Polimery 49, 432.

12. Deschamps, A.A., Grijpma, D.W. \& Feijen, J. (2001). Poly(ethylene oxide)/poly(butylene terephthalate) segmented block copolymers: the effect of copolymer composition on physical properties and degradation behavior, Polymer 42, 9335-9345. DOI: 10.1016/S0032-3861(01)00453-0.

13. Kojio, K., Nonaka, Y., Masubuchi, T. \& Furukawa, M. (2004). Effect of the composition ratio of copolymerized poly(carbonate) glycol on the microphase-separated structures and mechanical properties of polyurethane elastomers, J. Polym. Sci. Part B Polym. Phys. 42, 4448-4458. DOI: 10.1002/polb.20303.

14. El Fray, M. \& Słonecki, J. (1999). Multiblock terephthalate copolymer as impact modifier for poly (propylene)/ poly(butylene terephthalate) blends. Die Angew Makromol Chemie 266, 30-36. 